\title{
Effect of Na Substitution on Superconducting Properties of Bi-2212 Ceramics prepared
} by Sinter-Forged Process

\author{
O. Nane ${ }^{\text {a }}$, B. Özçelik ${ }^{\mathrm{b}}$, A. Sotelo ${ }^{\mathrm{c}}$, M. A. Madre ${ }^{\mathrm{c}}$ \\ ${ }^{a}$ Department of Material Science and Engineering, Faculty of Engineering, Hakkari \\ University, 30000 Hakkari, Turkey \\ ${ }^{\mathrm{b}}$ Department of Physics, Faculty of Sciences and Letters, Çukurova University. 01330 Adana, \\ Turkey \\ ${ }^{\mathrm{c}}$ ICMA (CSIC-Universidad de Zaragoza). María de Luna, 3. 50018 Zaragoza, Spain.
}

\begin{abstract}
s
Bulk textured $\mathrm{Bi}_{2} \mathrm{Sr}_{2} \mathrm{Ca}_{1-x} \mathrm{Na}_{x} \mathrm{Cu}_{2} \mathrm{O}_{y}(\mathrm{x}=0.0,0.05,0.075$ 0.1, 0.15, and 0.20) ceramics have been prepared by a polymer solution method followed by sinter-forging process. The microstructure and superconducting properties of textured samples were affected by $\mathrm{Na}$ substitution. According to XRD data, all samples show that Bi-2212 phase is the major one, and main peaks corresponded to the (00) diffractions confirming that the crystallographic caxis is perpendicular to the surface. SEM micrographs showed that samples are composed of well-stacked and oriented grains. The best critical temperature, $T_{C}$, was measured as $85.6 \mathrm{~K}$ for $\mathrm{x}=0.075$. The critical current density $J c$, values decrease gradually with the increase of applied magnetic field. The maximum calculated $J c$ was $1.38 \times 105 \mathrm{~A} / \mathrm{cm}_{2}$ at $10 \mathrm{~K}$ for $0.075 \mathrm{Na}$ sample which is about four times higher than the $0.34 \times 105 \mathrm{~A} / \mathrm{cm}_{2}$ value determined for the pure sample. The anisotropic properties of these textured materials have been investigated using magnetic measurements.
\end{abstract}

\section{Keywords}

Bi-2212; Sodium Substitution; Texturing; Anisotropy; Sinter-Forging Method. 


\section{Introduction}

Since Maeda's work [1] on superconductivity in the Bi-Sr-Ca-Cu-O (BSCCO) system, significant effort has been focused towards the improvement of their physical properties. This intense work has allowed determining that the BSCCO family comprises three superconducting phases. The general stoichiometry can be described as $\mathrm{Bi}_{2} \mathrm{Sr}_{2} \mathrm{Ca}_{n-1} \mathrm{Cu}_{n} \mathrm{O}_{2 n+4+}$ $\delta$, where $n=1,2$ and 3, with $T c$ values around 20,90 and $110 \mathrm{~K}$, respectively. These three phases are referred to as $\mathrm{Bi}-2201(n=1), \mathrm{Bi}-2212(n=2)$ and $\mathrm{Bi}-2223(n=3)$. The synthesis of pure $\mathrm{Bi}-2201$ and $\mathrm{Bi}-2212$ phases in this system is relatively easy, while the Bi-2223 single phase production has been shown to be a difficult task. As a consequence, the development of synthesis procedures which can lead to single phase ceramics, with a well defined $T \mathrm{c}$, has been a main objective in many works.

On the other hand, when considering practical applications, the fabrication of high temperature superconductors having high electrical transport capacity at $77 \mathrm{~K}$ is of great interest [2]. In particular, BSCCO family has been found suitable for many transport applications when they are properly processed in order to obtain a good grain orientation $[3,4]$. In order to enhance the critical temperature $(T c)$ and transport critical current $\left(J_{c}\right)$, many techniques were used leading to high performance materials, such as thin $[5,6]$ and thick film [7] technology, wires and tapes by the PIT method [8], and texturation using the Bridgman [9], Laser Floating Zone (LFZ) method [10-16], or the newer Electrically Assisted Laser Floating Zone method [17-20].

Among these techniques successfully used to produce well textured materials [21-23], the directional growth from the melt by the LFZ method has demonstrated to be a very useful technique for producing well textured BSCCO rods at high growth rates. As it was previously reported [13], the microstructure of the superconducting ceramics is characterized by a good grain alignment, with their $c$-axis quasi-perpendicular to the growth direction. This high degree of texture leads to a very important increase of the transport properties, $J \mathrm{c}$, due to the reduction of the number of low-angle junctions [24]. After the growth process, due to the incongruent melting of this phase [25], it is necessary to subject the samples to an annealing process to produce the Bi-2212 phase from the secondary ones [26]. However, the poor mechanical properties of superconducting materials impose severe limitations to their practical applications. In order to improve their mechanical behavior, high Ag additions have been performed on BSCCO sintered materials [27], while the optimum Ag amount necessary to improve mechanical properties in LFZ textured materials is much lower (1-3 wt.\%) [26] due to their lower porosity. 
On the other hand, the hot-forging technique [21] has also been successfully used to obtain bulk monoliths of high-Tc superconductors with well-textured grains. Using this process, it is possible to perform a good grain orientation, with the crystallographic $c$-axis along the press axis, enhancing the critical current, $J \mathrm{c}$, values when measured along the $a b$ plane.

Experimental studies related to hot-pressing processes have already been carried out on different kind of samples using different pressures and heat treatments. In these works, it has been found that the results mainly depend on the applied temperature during the pressing process. If the temperature is too low to form a minimal liquid phase, the process does not offer the necessary conditions to produce high densification and grain orientation. On the other hand if the temperature is too high, a melt will be obtained, leading to glassy materials by quenching [21].

In previous works, $\mathrm{Bi}_{2} \mathrm{Sr}_{2} \mathrm{Ca}_{1-\mathrm{x}} \mathrm{Na}_{2} \mathrm{Cu}_{2} \mathrm{O}_{8}+\delta$ bulk and textured ceramics with different $\mathrm{Na}$ content, prepared by a polymer solution method and the LFZ technique, respectively [28,29], have been studied. The effect of $\mathrm{Na}$ on the microstructural features, critical temperature $T_{C}$, magnetic properties and magnetic $J_{C}$ have been determined. As a consequence of these previous results, the aim of this work is producing $\mathrm{Bi}_{2} \mathrm{Sr}_{2} \mathrm{Ca}_{1-\mathrm{x}} \mathrm{Na}_{x} \mathrm{Cu}_{2} \mathrm{O} x$ with $\mathrm{x}=0.0,0.05$, $0.075,0.10,0.15$ and 0.20 textured materials, using the hot-forging technique in order to determine the best texturing procedure for these materials preparation.

\section{Experimental}

$\mathrm{Bi}_{2} \mathrm{Sr}_{2} \mathrm{Ca}_{1-x} \mathrm{Na}_{x} \mathrm{Cu}_{2} \mathrm{O}_{x}$ polycrystalline precursors were prepared from $\mathrm{Bi}\left(\mathrm{CH}_{3} \mathrm{COO}\right)_{3}(\geq 99.99$ \%, Aldrich), $\mathrm{Sr}\left(\mathrm{CH}_{3} \mathrm{COO}\right)_{2} \bullet 0.5 \mathrm{H}_{2} \mathrm{O}(99 \%$, Panreac $), \mathrm{Ca}\left(\mathrm{CH}_{3} \mathrm{COO}\right)_{2} \bullet 2 \mathrm{H}_{2} \mathrm{O}(98 \%$, Alfa Aesar), $\mathrm{Na}\left(\mathrm{CH}_{3} \mathrm{COO}\right) \cdot 3 \mathrm{H}_{2} \mathrm{O}(\geq 99.99 \%$, Aldrich $)$, and $\mathrm{Cu}\left(\mathrm{CH}_{3} \mathrm{COO}\right)_{2} \bullet \mathrm{H}_{2} \mathrm{O}(98 \%$, Panreac) commercial powders using a polymer solution method [30]. They were weighed in stoichiometric proportions and dissolved in a mixture of glacial acetic acid (ACS Reagent, Panreac) and distilled $\mathrm{H}_{2} \mathrm{O}$. Once a clear solution has been produced, PEI (polyethyleneimine, $50 \%$ aqueous, Aldrich) was added to produce the cations coordination with PEI. The complexes formation is reflected in the solution color change, from clear blue due to the presence of $\mathrm{Cu}^{2+}$ to a deep blue from the nitrogen- $\mathrm{Cu}^{2+}$ coordination bonds [31]. The solution was then concentrated to around $20 \mathrm{vol} . \%$ of the original one by evaporation in a rotary evaporator. Total solvent evaporation has been performed onto a hot plate at around $80{ }^{\circ} \mathrm{C}$ until a thermoplastic deep blue paste has been produced [32]. Further heating at around 350 ${ }^{\circ} \mathrm{C}$ produces its decomposition by self combustion, releasing brown fumes (due to nitrogen oxides), and reaching temperatures of around $750{ }^{\circ} \mathrm{C}$ inside the crucible. The obtained 
powders mixture was milled and thermally treated at 750 and $800{ }^{\circ} \mathrm{C}$ for $12 \mathrm{~h}$ with an intermediate manual milling to favour the alkaline-earth carbonates decomposition as previously reported [26].

The calcined powders were then uniaxially pressed at about $350 \mathrm{MPa}$ in form of disks $(25 \mathrm{~mm}$ diameter and 2-2.5 mm thick) which were subsequently textured using a hot-pressing installation [21]. The processing conditions were fixed at $800^{\circ} \mathrm{C}$ and about $20 \mathrm{MPa}$ for $15 \mathrm{~h}$ with a final furnace cooling. After the texturing processes, the disks showed bigger diameter (around $30 \mathrm{~mm}$ ) and lower thickness $(1-1.2 \mathrm{~mm})$. On the other hand, as previously mentioned this process produces a small amount of liquid phase, leading to a partial Bi-2212 phase decomposition. As a consequence, a subsequent thermal treatment has been shown to be necessary in order to produce nearly Bi-2212 pure phase materials. This treatment consisted in two steps: $60 \mathrm{~h}$ at $860^{\circ} \mathrm{C}$ to produce the $\mathrm{Bi}-2212$ phase, followed by $12 \mathrm{~h}$ at $800{ }^{\circ} \mathrm{C}$ to adjust the oxygen content and, finally, quenched in air to room temperature.

Structural studies of textured ceramic samples were performed by using a Rigaku D/max-B $\mathrm{X}$-ray powder diffractometer ( $\mathrm{CuK} \alpha$ radiation) with $2 \theta$ ranging between 3 and 80 degrees. The uncertainty of the crystal lattice parameters calculation remained in the \pm 0.00001 range. Microstructural characterization was performed on fractured transversal cross-sections and on the samples surface, in a field emission scanning electron microscope (FESEM, Zeiss Merlin) equipped with an energy dispersive spectroscopy (EDX) system. The magnetic hysteresis and virgin curve measurements of samples were performed at $10 \mathrm{~K}$ and of $\pm 1 \mathrm{~T}$ an applied field. Moreover, M(T) measurements under 100 Oe applied field in ZFC mode were made in a 7304 Lake Shore VSM.

\section{Results and Discussion}

Fig. 1 shows the normalized powder XRD patterns of all samples between $3^{\circ}-80^{\circ}$. As it can be observed in the figure, the most intense peaks correspond to the (00l) planes of Bi-2212 phase [33] in all cases, clearly indicating that most of the grains have their c-axis oriented parallel to the applied pressure direction. The unit-cell parameters and average crystal sizes were calculated by using the Debye-Scherrer formula [34], and displayed in Table 1. The crystal symmetries of all samples showed a pseudo-tetragonal structure with $a-b \approx 5.40 \dot{\mathrm{A}}$. The calculated crystal sizes have been increased by Na doping, when compared to the undoped samples. As a consequence, it can be deduced that $\mathrm{Na}$ substitution can be helpful to raise the grain growth rates, leading to a decrease in the number of grain boundaries. This effect can be 
due to the fact that $\mathrm{Na}$ substitution decreases the system melting point, inducing the formation of a small amount of liquid phase, speeding up the diffusion rate, producing larger grains. Fig. 2 shows the SEM micrographs of cross-sectional fractured sections perpendicular to the pressing direction. In these general views, it can be easily observed that grains are very well stacked along their a-b plane with no evident porosity among them. Moreover, they clearly show a marked preferential orientation already described in the XRD data [35,36]. The effect of $\mathrm{Na}$ doping can be seen in the larger grain sizes of these samples, compared with the undoped ones, in a clear agreement with previously published data [28,29,37]. Especially, $0.05,0.075$, and $0.1 \mathrm{Na}$ substituted samples possess larger angles between adjacent grains which imply better intergranular characteristics. It should be noted that these dense and textured structures are very important in high- $T_{C}$ superconductors, as the BSCCO system, due to the fact that low angles between grains drastically decrease the electrical and magnetical properties. Other important observed effect of $\mathrm{Na}$ doping is related to the grains thickness when they are measured in several SEM micrographs. Grains thickness is firstly increased by Na doping until 0.075, while further substitution stars to decrease it. The mean values obtained for these grain thicknesses were $910,950,1300,1010,860$, and $600 \mu \mathrm{m}$, for 0.0 , $0.05,0.075,0.10,0.15$, and $0.20 \mathrm{Na}$ substitutions, respectively.

Fig. 3 shows representative SEM micrographs performed on polished longitudinal sections of all samples, using backscattered electrons. As it can be observed in these micrographs, all samples show two main contrasts, each one associated by EDX to a different phase. The grey contrast (major one in all cases, indicated by \#1) has been assigned to the superconducting Bi2212 phase. On the other hand, dark grey contrasts correspond to non superconducting secondary phases (numbered as \#2 in the undoped sample and \#3 in the Na doped ones). The different numbers indicate changes in the secondary phase composition, which has been found as the metastable $(\mathrm{Sr}, \mathrm{Ca}) \mathrm{CuO}_{2}$ in the undoped samples, while it has been modified to the equilibrium $(\mathrm{Ca}, \mathrm{Sr}){ }_{14} \mathrm{Cu}_{24} \mathrm{O}_{41}(14: 24)$ phase when $\mathrm{Na}$ is present in the samples. These modifications clearly point out to important changes in the texturing process induced by $\mathrm{Na}$ substitution. These modifications have already been found in this system when it is textured using the EALFZ technique [20], leading to improved electrical transport properties. Fig. 4 shows the magnetizations curves, as a function of temperature, measured under $100 \mathrm{Oe}$ magnetic field, applied parallel to the stress axis of samples. The use of higher magnetic field than usual in a ZFC mode measurement for high- $T_{C}$ superconductors (10-50 Oe) has been made in order to get deeper information about the general samples texture. It can be obviously seen from the figure that the superconducting transition temperature, $T_{C}$ is around $85 \mathrm{~K}$ in all 
cases, with a slight variation depending on $\mathrm{Na}$ content. The best $T_{C}$ values were obtained in the $\mathrm{x}=0.075 \mathrm{Na}$ samples $(85.6 \mathrm{~K})$ which is $4.4 \mathrm{~K}$ higher than the obtained for the undoped ones. $M-T$ results clearly point out to an improvement of $T_{C}$ values with Na substitution, in agreement with the SEM discussions.

Fig. 5 shows the magnetic hysteresis loops determined at $10 \mathrm{~K}$ and $\pm 10 \mathrm{kOe}$ applied magnetic fields parallel to the stress direction, for all samples. As it can be easily seen in the graph, the loops first enlarge up to $0.075 \mathrm{Na}$ substitution and become narrower for further $\mathrm{Na}$ contents. Moreover, although $0.2 \mathrm{Na}$ substituted sample shows a paramagnetic signal around $5 \mathrm{kOe}$ magnetic field, indicating it is in normal state, the $M-H$ loops obtained for Na substituted samples are clearly larger than the obtained in the undoped samples. This effect can be associated to the larger grain sizes produced in $\mathrm{Na}$ doped samples which is the result of the higher amount of liquid phase in these samples induced by sodium. In addition, the symmetrical shape of these hysteresis curves at low applied magnetic field indicates that vortex pinning is dominated by bulk pinning rather than surface and/or geometrical barriers [38].

Fig. 6 shows the initial (virgin) DC magnetization curves as a function of the applied magnetic fields between 0 and $10 \mathrm{kOe}$, at $10 \mathrm{~K}$, for all samples. As it can be observed in the graph, at low applied fields (below $\mathrm{HCl}_{C l}$ ) the magnetic flux lines can only penetrate in the grain boundaries region where structural defects and/or chemical impurities interrupt flux line flow, known as vortex pinning effect. On the other hand, at fields higher than $\mathrm{HCl}_{\mathrm{C}}$ magnetic flux lines begin to significantly penetrate into the grains, leading to a significant decrease of $\mathrm{M}$. Moreover, in agreement with the previous discussions in Fig. 5, $0.20 \mathrm{Na}$ substituted samples show the superconducting to normal state transition at about $3.6 \mathrm{kOe}$ applied magnetic field. The highest $\mathrm{HCl}_{\mathrm{Cl}}$ values (1080 Oe) have been achieved for $0.075 \mathrm{Na}$ substituted samples due to their improved grain structure, discussed in SEM section.

From $M-H$ data, the intragranular $J c$ values of all samples were calculated using the Bean's model [39];

$$
J_{c}=\frac{60 a|\Delta M|}{b(3 a-b)}
$$

where $J_{C}$ is the critical current density in ampéres per square centimeter. $M=M_{+}-M_{-}$is measured in electromagnetic units per cubic centimeter, and $a$ and $b$ are the length of the sample plane perpendicular to the applied magnetic field. Fig. 7 shows the calculated critical current density values at $10 \mathrm{~K}$, up to $10 \mathrm{kOe}$, for all samples. In the figure, it can be seen that intragranular $J_{c}$ values gradually decrease when the applied magnetic field is increased. The 
maximum critical current density $J c$ has been achieved for the $0.075 \mathrm{Na}$ doped samples $\left(1.38 \times 10^{5} \mathrm{~A} / \mathrm{cm}^{2}\right.$ at $\left.10 \mathrm{~K}\right)$ which is around four times higher than the obtained for undoped ones $\left(0.34 \times 10^{5} \mathrm{~A} / \mathrm{cm}^{2}\right)$. The higher intragranular $J_{C}$ values for all Na-substituted samples, compared with the undoped ones, are due to the better texture and larger grain size induced by Na substitution. Moreover, it can be observed that $J_{C}$ values for $0.075 \mathrm{Na}$ doped samples are higher than $0.10 \mathrm{Na}$ doped ones at low magnetic fields, but then it becomes lower at higher applied field values. The reason of this behavior can be found in the larger grains observed in the SEM micrographs for the $0.10 \mathrm{Na}$ doped samples, leading to a lower number of grain boundaries and improving the diamagnetic behavior at high applied magnetic fields. Fig. 8 shows the magnetic hysteresis loops obtained under parallel $(H / / c)$ and perpendicular $(H\lrcorner c)$ applied magnetic fields with respect to the $c$-axis. In the figure, it can be clearly observed that the magnetic hysteresis loop obtained when the applied field is parallel to the stress axis is larger than the perpendicular one due to the typical anisotropy of BSCCO high$T_{C}$ superconductors. The difference between these curves shows an important anisotropy in the bulk material, confirming the good grains orientation already seen in SEM micrographs. From these data, the anisotropy factor has been calculated through the expression: $\Delta \mathrm{M} / / / \Delta \mathrm{M} \perp$ where $\Delta \mathrm{M} / /$ and $\Delta \mathrm{M} \perp$ are the widths of hysteresis loops at zero field. The obtained value, 5.15, clearly indicates the good texture obtained in these samples.

Fig. 9 shows the angular dependence of dc magnetization for the $0.075 \mathrm{Na}$ substituted sample under 100 Oe applied field at $10 \mathrm{~K}$. The result verifies the well-known anisotropic behavior of BSCCO high- $T_{C}$ superconductors. Whenever applied magnetic field is parallel to the $c$-axis ( $\beta=0^{\circ}$ ), diamagnetic response is maximum, then while angle goes forward to the perpendicular direction, dc magnetization linearly decreases until the minimum diamagnetic response at $\beta=90^{\circ}$. From these data, anisotropy factor has been calculated using the expression $M_{\beta=0} / M_{\beta}=90$, where $M_{\beta=0}$ and $M_{\beta}=90$ are the dc magnetization signal for $\beta=0^{\circ}$ and $\beta=90^{\circ}$ respectively. The high obtained value (14.6) can be related to the well oriented grains in these samples.

\section{Conclusion}

In this study, $\mathrm{Bi}_{2} \mathrm{Sr}_{2} \mathrm{Ca}_{1-x} \mathrm{Na}_{x} \mathrm{Cu}_{2} \mathrm{O}_{y}$ ceramic materials have been successfully textured using the sinter-forging technique. The $\mathrm{Na}$ substitution for $\mathrm{Ca}$ has an important effect on the texture and grain sizes of these samples, leading to a significant improvement of calculated $J_{C}$ values. The XRD and SEM results confirmed these structural and microstructural features. EDX 
results indicate that $\mathrm{Bi}-2212$ is the major phase, accompanied by relatively low amounts of secondary phases. Moreover, it has pointed out to important changes in the secondary phases composition, from the metastable $(\mathrm{Ca}, \mathrm{Sr}) \mathrm{CuO}_{2}$ in undoped samples, to the equilibrium one $(\mathrm{Ca}, \mathrm{Sr}){ }_{14} \mathrm{Cu}_{24} \mathrm{O}_{41}$ when $\mathrm{Na}$ is added. According to magnetization results, $0.075 \mathrm{Na}$ sample is the optimum $\mathrm{Na}$ amount for producing the best superconducting properties. The highest $J_{C}$ and $T_{C}$ determined values have been $1.38 \times 10^{5} \mathrm{~A} / \mathrm{cm}^{2}$ and $85.6 \mathrm{~K}$ respectively. Furthermore, hysteresis loops obtained for $H / / c$ and $H\lrcorner_{c}$ have shown the high anisotropic behaviors by a factor value of 5.15 which means well textured intragrain regions in $0.075 \mathrm{Na}$ sample. In order to obtain, in detail, the superconducting properties affected by texturing process via sinter forging technique, the angular dependent magnetic measurement was performed on $0.075 \mathrm{Na}$ sample which is an effective tool to characterize anisotropy. The anisotropy factor has been calculated as 14.6 by $M_{\beta=0} / M_{\beta}=90$ formula.

\section{Acknowledgement}

This work is supported by Research Fund of Çukurova University, Adana, Turkey, under grant contracts no: FBA-2014-3500. A. Sotelo and M. A. Madre acknowledge the Gobierno de Aragón and Fondo Social Europeo (Grupo de Investigacion Consolidado T12) and MINECO-FEDER (MAT2013-46505-C3-1-R) for financial support. M. A. Madre also acknowledges MINECO-FEDER (Project ENE2014-52105-R) for funding. Authors would like to acknowledge the use of Servicio General de Apoyo a la Investigación-SAI, Universidad de Zaragoza. This work is supported by Research Fund of Hakkari University, Hakkari, Turkey, under grant contracts no: MF2014BAP1.

\section{References}

[1] H. Maeda, Y. Tanaka, M. Fukutumi, T. Asano, A new high-Tc oxide superconductor without a rare-earth element, Jpn. J. Appl. Phys. 27, 209 (1988)

[2] M. Chen, L. Donzel, M. Lakner, W. Paul, High temperature superconductors for power applications, J. Eur. Ceram. Soc. 24, 1815 (2004)

[3] Hermann, P.F.: Handbook of Applied Superconductivity. IOP Publishing, Bristol (1998)

[4] M. Noe, K. P. Juengst, F. Werfel, S. Elschner, J. Bock, F. Breuer, R. Kreutz, Testing bulk HTS modules for resistive superconducting fault current limiters, IEEE Trans. Appl. Supercond. 13, 1976 (2003) 
[5] K. Konstantinov, I. Stambolova, P. Peshev, A. Souleva, T. Tsacheva, G. Gyurov, I. Khristova, Variations in the chemical composition of $\mathrm{Bi}(\mathrm{Pb})-\mathrm{Sr}-\mathrm{Ca}-\mathrm{Cu}-\mathrm{O}$ films deposited by spray pyrolysis method, J. Anal. Appl. Pyrolysis 42 (1997) 89.

[6] V. M. Vereshchaka, A. A. Onoprienko, L. R. Shaginyan, Analysis of film composition in $\mathrm{Sr}-\mathrm{Bi}-\mathrm{Ca}-\mathrm{Cu}-\mathrm{Pb}-\mathrm{O}$ system, produced by magnetron sputtering, Poroshk. Metall. 56 (1996) 27.

[7] C. L. Carvalho, D. I. Santos, E. A. A. Rubo, M. A. Aegerter, The sintering time influence on the structural and electrical characteristics of the $\mathrm{Bi} \mathrm{Sr} \mathrm{Ca} \mathrm{Cu} \mathrm{O}$ system superconducting ceramic, Program Ext. Abstr.-Int. Workshop Supercond. 406 (1995)

[8] S. Li, M. Bredehöft, W. Gao, H.K. Liu, T. Chandra, S.X. Dou, The formation and distribution of texture microstructure produced by mechanical deformation in silver-sheathed BSCCO superconductors, Supercond. Sci. Technol. 11 (1998) 1011

[9] M. Nevriva, V. Sima, E. Pollert, J. Chval, J. Hejtmanek, Preparation and properties of textured BSCCO samples, China J. Phys. 34 (1996) 320

[10] R. S. Feigelson, D. Gazit, D. K. Fork, T. H. Geballe, Laser-Heated Pedestal Growth Method, Science 240, 1642 (1988)

[11] Y. Huang, G.F. de la Fuente, A. Sotelo, A. Bad'ia, F. Lera, R. Navarro, C. Rillo, R. Ibanez, D. Beltran, F. Sapina, A. Beltran, $(\mathrm{Bi}, \mathrm{Pb}) 2 \mathrm{Sr} 2 \mathrm{Ca} 2 \mathrm{Cu} 3 \mathrm{O} 10+\delta$ Superconductor composites: Ceramic vs. Fibers, Physica C 185, 2401-2402 (1991)

[12] M. Mora, A. Sotelo, H. Amaveda, M. A. Madre, J. C. Diez, F. Capel, J. M. LopezCepero, Properties variation of Bi-2212 directionally solidified induced by $0.4 \mathrm{~Pb}$ substitution, J. Eur. Ceram. Soc. 27, 3959-3962 (2007)

[13] G. F. de la Fuente, M.T. Ruiz, A. Sotelo, A. Larrea, R. Navarro, Microstructure of laser floating zone (LFZ) textured ( $\mathrm{Bi}, \mathrm{Pb})-\mathrm{Sr}-\mathrm{Ca}-\mathrm{Cu}-\mathrm{O}$ superconductor composites, Mater. Sci. Eng. A 173, 201-204 (1993)

[14] B. Özçelik, B. Özkurt, M.E. Yakıncı, A. Sotelo, M. A. Madre, Relationship Between Annealing Time and Magnetic Properties in Bi-2212 Textured Composites, J. Supercond. Nov. Magn. 26, 873-878 (2013)

[15] H. Miao, J.C. Diez, L.A. Angurel, J.I. Peña, G.F. de la Fuente, Phase formation and microstructure of laser floating zone grown BSCCO fibers: reactivity aspects, Solid State Ionics, Volumes 101-103, Part 2, Pages 1025-1032 (1997)

[16] L.A. Angurel, J.C. Díez, E. Martínez, J.I. Peña, G.F. de la Fuente, R. Navarro, Growth rate effects on thin $\mathrm{Bi} 2 \mathrm{Sr} 2 \mathrm{CaCu} 2 \mathrm{O} 8+\delta$ textured rods, Physica C: Superconductivity, Volume 302, Issue 1, Pages 39-50 (1998) 
[17] M.F. Carrasco, R.A. Silva, N.J.O. Silva, R.F. Silva, J.M. Vieira, F.M. Costa, Radial inhomogeneities induced by fiber diameter in electrically assisted LFZ growth of Bi-2212, Applied Surface Science, Volume 255, Issue 10, Pages 5503-5506 (2009)

[18] M.F. Carrasco, V.S. Amaral, R.F. Silva, F.M. Costa, Electrical assisted laser floating zone (EALFZ) growth of 2212-BSCCO superconducting fibres, Applied Surface Science, Volume 257, Issue 12, Pages 5283-5286 (2011)

[19] J.M. Vieira, R.A. Silva, R.F. Silva, F.M. Costa, Enhancement of superconductivity in LFZ-grown BSCCO fibres by steeper axial temperature gradients, Applied Surface Science, Volume 258, Issue 23, Pages 9175-9180 (2012)

[20] F. M. Costa, N. M. Ferreira, Sh. Rasekh, A. J. S. Fernandes, M. A. Torres, M. A. Madre, J. C. Diez, A. Sotelo, Very large superconducting currents induced by growth tailoring, Crystal Growth Design 15, 2094-2101 (2015)

[21] V. Garnier, R. Caillard, A. Sotelo, G. Desgardin, Relationship among synthesis, microstructure and properties in sinter-forged Bi-2212 ceramics, Physica C 319, 197 (1999) [22] Martin-Gonzalez, M.S., Garcia-Jaca, J., Moran, E., Alario-Franco, M.A., Formation of Bi-Sr-Ca-Cu-O superconducting films by electrodeposition, J. Mater. Res. 14, 3497 (1999)

[23] H. Maeda, K. Ohya, M. Sato, W. P. Chen, K. Watanabe, M. Motokawa, A. Matsumoto, H. Kumakura, J. Schwartz, Microstructure and critical current density of Bi2212 tapes grown by magnetic melt-processing, Physica C 382, 33 (2002)

[24] D. Shi, High Temperature Superconducting Materials Science and Engineering. Oxford, Pergamon Press (1995)

[25] K. Schulze, P. Majewski, B. Hettich, G. Petzow, Phase equilibria in the system $\mathrm{Bi}_{2} \mathrm{O}_{3^{-}}$ SrO-CaO-CuO with emphasis on the High- $\mathrm{T}_{\mathrm{C}}$ superconducting compounds, Z. Metallkd. 81, 836-842 (1990)

[26] A. Sotelo, M. Mora, M. A. Madre, J. C. Diez, L. A. Angurel, G. F. de la Fuente, Ag distribution in thick Bi-2212 floating zone textured rods, J. Eur. Ceram. Soc. 25, 2947-2950 (2005)

[27] A. Salazar, J. Y. Pastor, J. Llorca, Strength and fracture toughness of hot-pressed bulk $\mathrm{Bi}_{2} \mathrm{Sr}_{2} \mathrm{Ca}_{2} \mathrm{Cu}_{3} \mathrm{O} x$ and $\mathrm{Bi}_{2} \mathrm{Sr}_{2} \mathrm{Ca}_{2} \mathrm{Cu}_{3} \mathrm{O} x / \mathrm{Ag}$ at 77 and $300 \mathrm{~K}$, Physica C 385, 404 (2003)

[28] M. Gürsul, A. Ekicibil, B. Özçelik, M. A. Madre, A. Sotelo, Sintering Effects in NaSubstituted Bi-(2212) Superconductor Prepared by a Polymer Method, J. Supercond. Nov. Magn. 28, 1913-1924 (2015) 
[29] O. Nane, B.Özçelik, H.Amaveda, A.Sotelo, M.A.Madre, Improvement of structural and superconducting properties of Bi-2212 textured rods by substituting sodium, Ceram. Int. 42, 8473-8477 (2016)

[30] A. Sotelo, Sh. Rasekh, M. A. Madre, J. C. Diez. Precursor Influence on the Electrical Properties of Textured Bi-2212 Superconductors. J. Supercond. Nov. Magn. 24, 19-25 (2011) [31] A. Sotelo, H. Szillat, P. Majewski, F. Aldinger. Rapid synthesis of the Bi-2212 phase by a polymer matrix method. Supercond. Sci. Technol. 10, 717-720 (1997)

[32] A. Sotelo, J. I .Peña, L. A. Angurel, C. Diez, M. T. Ruiz, G. F. de la Fuente, R. Navarro, Synthesis of the $\mathrm{Bi}_{2} \mathrm{Sr}_{2} \mathrm{CaCu}_{2} \mathrm{O}_{8+\delta}$ superconductor following a polymer matrix route, J. Mater. Sci. 32, 5679-5685 (1997)

[33] O. Nane, B. Özçelik, D. Abukay, The effects of the post-annealing temperature on the growth mechanism of $\mathrm{Bi} 2 \mathrm{Sr} 2 \mathrm{Ca} 1 \mathrm{Cu} 2 \mathrm{O} 8+\partial$ thin films produced on $\mathrm{MgO}\left(\begin{array}{lll}1 & 0 & 0\end{array}\right)$ single crystal substrates by pulsed laser deposition (PLD), Journal of Alloys and Compounds, Volume 566, Pages 175-179 (2013)

[34] P. Scherrer, Bestimmung der Größe und der inneren Struktur von Kolloidteilchen mittels Röntgenstrahlen, Göttinger Nachrichten Gesell 2 (1918)

[35] S. Pavard, D. Bourgault, C. Villard, R. Tournier, Critical current density of $165 \mathrm{kA} / \mathrm{cm}^{2}$ at $4 \mathrm{~K}$ in bulk Bi2212/MgO textured by solidification in a high magnetic field and hot forging, Physica C 316, 198-204 (1999)

[36] R. Caillard, V. Garnier, G. Desgardin, Sinter-forging conditins, texture and transport properties of Bi-2212 superconductors, Physica C 340, 101-111 (1999)

[37] B. Özçelik, M. Gürsul, A. Sotelo, M. A. Madre, Improvement of superconducting properties in Na-doped BSCCO superconductor, J. Mater. Sci.: Mater. Electron. 26, 441-447 (2015)

[38] B. Chevalier, B. Lepine, A. Lalerzin, J. Darriet, J. Eournau, J.M. Tarascon, Superconducting Properties of Substituted Oxides $\mathrm{Bi}_{2} \mathrm{Sr}_{2}\left({ }_{(1-\mathrm{x}) \mathrm{Yx}}\right) \mathrm{Cu}_{2} \mathrm{O}_{8+\mathrm{Y}}$, Mater. Sci. Eng. B, 1. B2, 4 (1989), pp. 277-280

[39] C.P. Bean, Magnetization of Hard Superconductors, Phys. Rev. Lett. 8, 250 (1962) 


\section{Figure Captions}

Figure 1. Powder XRD patterns of all samples. Diffraction planes correspond to the Bi-2212 phase.

Figure 2. Representative SEM micrographs performed on transversal fractured sections of all $\mathrm{Bi}_{2} \mathrm{Sr}_{2} \mathrm{Ca}_{1-\mathrm{x}} \mathrm{Na}_{\mathrm{x}} \mathrm{Cu}_{2} \mathrm{O}_{\mathrm{y}}$ samples, with $\left.\mathrm{x}=\mathrm{a}\right) 0$; b) 0.05 ; c) 0.075 ; d) 0.10; e) 0.15; and e) 0.20. Figure 3. Representative SEM micrographs performed on longitudinal polished sections of $\mathrm{Bi}_{2} \mathrm{Sr}_{2} \mathrm{Ca}_{1-\mathrm{x}} \mathrm{Na}_{\mathrm{x}} \mathrm{Cu}_{2} \mathrm{O}_{\mathrm{y}}$ samples with $\mathrm{x}=\mathrm{a}$ ) 0 ; b) 0.05; c) 0.075; d) 0.10; e) 0.15; and e) 0.20. Numbers indicate the different phases: 1) $\mathrm{Bi}-2212 ; 2)(\mathrm{Sr}, \mathrm{Ca}) \mathrm{CuO}_{2}$; and 3) $\left(\mathrm{Ca}, \mathrm{Sr}{ }_{14} \mathrm{Cu}_{24} \mathrm{O}_{41}\right.$ Figure 4. Magnetic moment as a function of temperature for all samples.

Figure 5. Magnetic Hysteresis curves obtained for all samples at $10 \mathrm{~K}$.

Figure 6. Magnetic initial curves obtained for all samples at $10 \mathrm{~K}$.

Figure 7. Calculated critical current densities, $J c$, of all samples at $10 \mathrm{~K}$, as a function of the applied field.

Figure 8. Anisotropic magnetic hysteresis curves obtained for $0.075 \mathrm{Na}$-substituted samples at $10 \mathrm{~K}$.

Figure 9. Magnetic moment versus $\beta$ angle between applied field and stress axis of $0.075 \mathrm{Na}$ substituted sample for $-10^{\circ}<\beta<180^{\circ}$. 


\section{Table}

Table 1. $T_{C}$ values determined from $M-T$ measurement, unit-cell parameters, crystal sizes, and magnetic $J c$ values for all samples.

\begin{tabular}{|l|c|c|c|c|}
\hline Na-Content & $\boldsymbol{T}_{\boldsymbol{C}}(\mathbf{K})$ & $\begin{array}{l}\text { Unit-cell } \\
\text { Parameter } \\
\boldsymbol{a} \approx \boldsymbol{b}(\dot{\mathbf{A}})\end{array}$ & $\begin{array}{l}\text { Unit-cell } \\
\text { Parameter } \\
\boldsymbol{c}(\dot{\mathbf{A}})\end{array}$ & $\begin{array}{l}\text { Max. } \\
\text { Intragranular } \\
\mathbf{J}_{\mathbf{C}}\left(\mathbf{A} / \mathbf{c m}^{2}\right) \\
\mathbf{1 0 ~ K}\end{array}$ \\
\hline $\mathrm{x}=0.000$ & 81.2 & 5.4127 & 30.7236 & $0.34 \times 10^{5}$ \\
\hline $\mathrm{x}=0.050$ & 84.9 & 5.3925 & 30.8883 & $0.78 \times 10^{5}$ \\
\hline $\mathrm{x}=0.075$ & 85.6 & 5.4085 & 30.8871 & $1.38 \times 10^{5}$ \\
\hline $\mathrm{x}=0.100$ & 83.2 & 5.3925 & 30.8830 & $1.30 \times 10^{5}$ \\
\hline $\mathrm{x}=0.150$ & 82.1 & 5.4212 & 30.8192 & $0.57 \times 10^{5}$ \\
\hline $\mathrm{x}=0.200$ & 81.9 & 5.3672 & 30.8863 & $0.58 \times 10^{5}$ \\
\hline
\end{tabular}


Figure 1

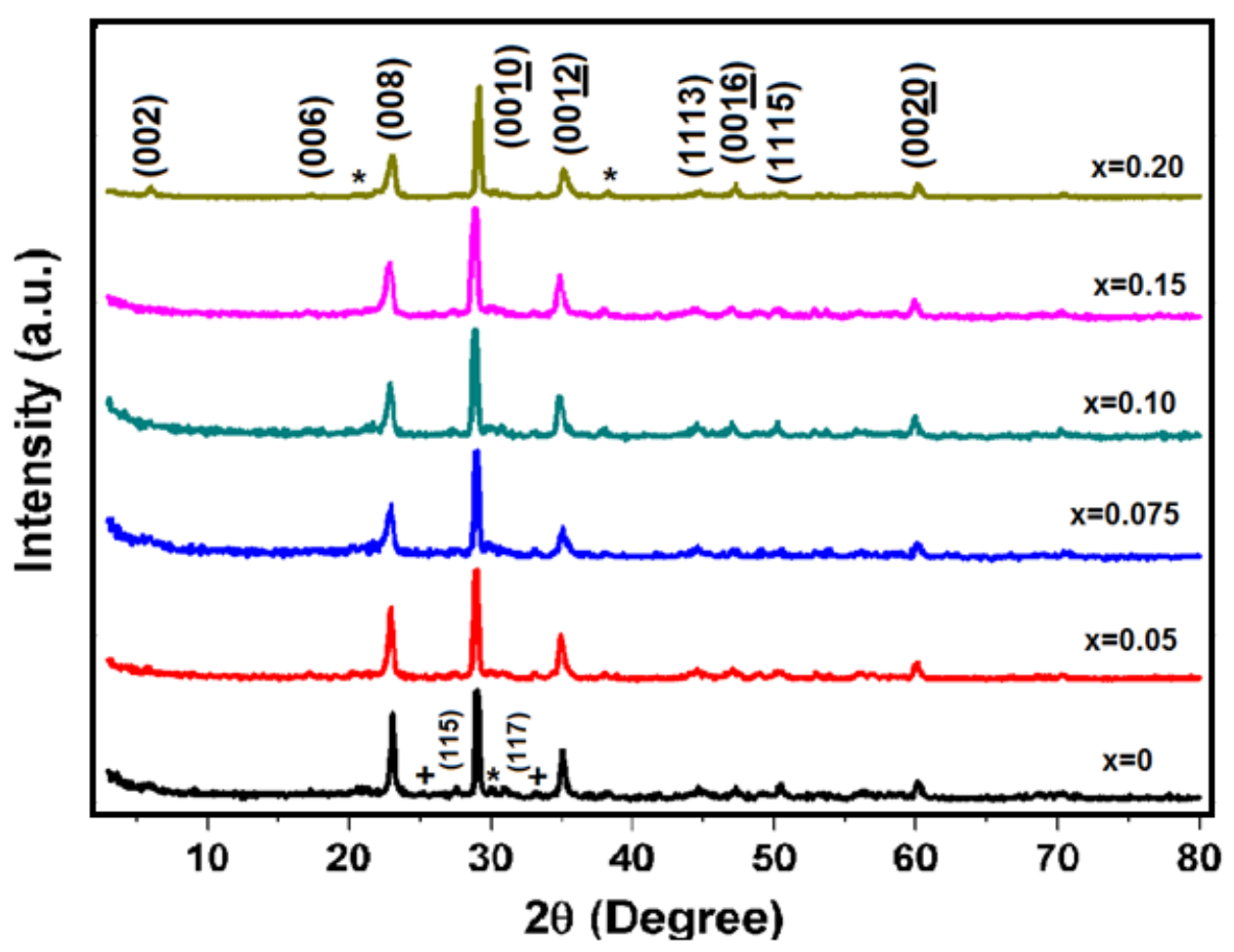




\section{Figure 2}
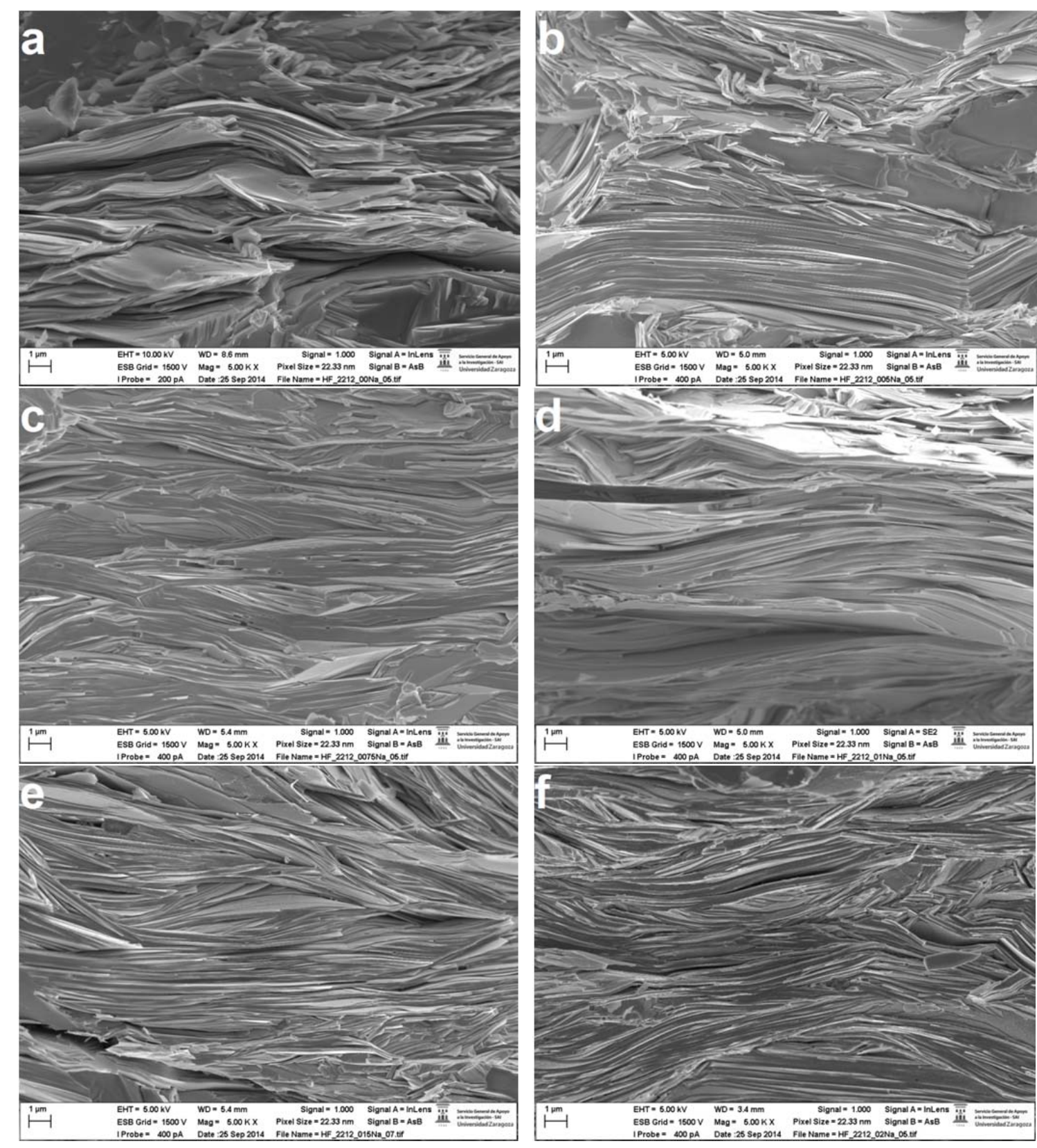
Figure 3
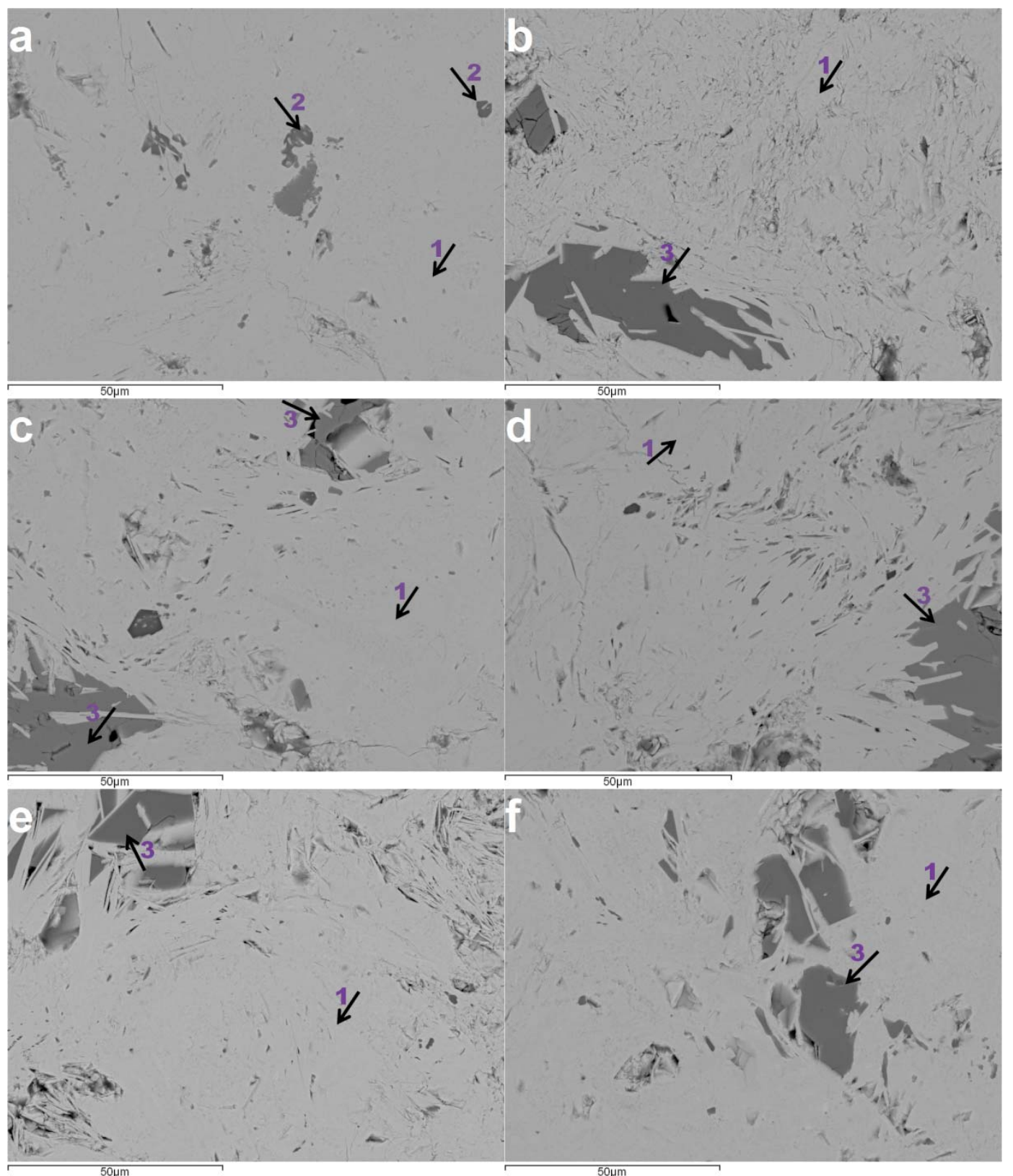
Figure 4

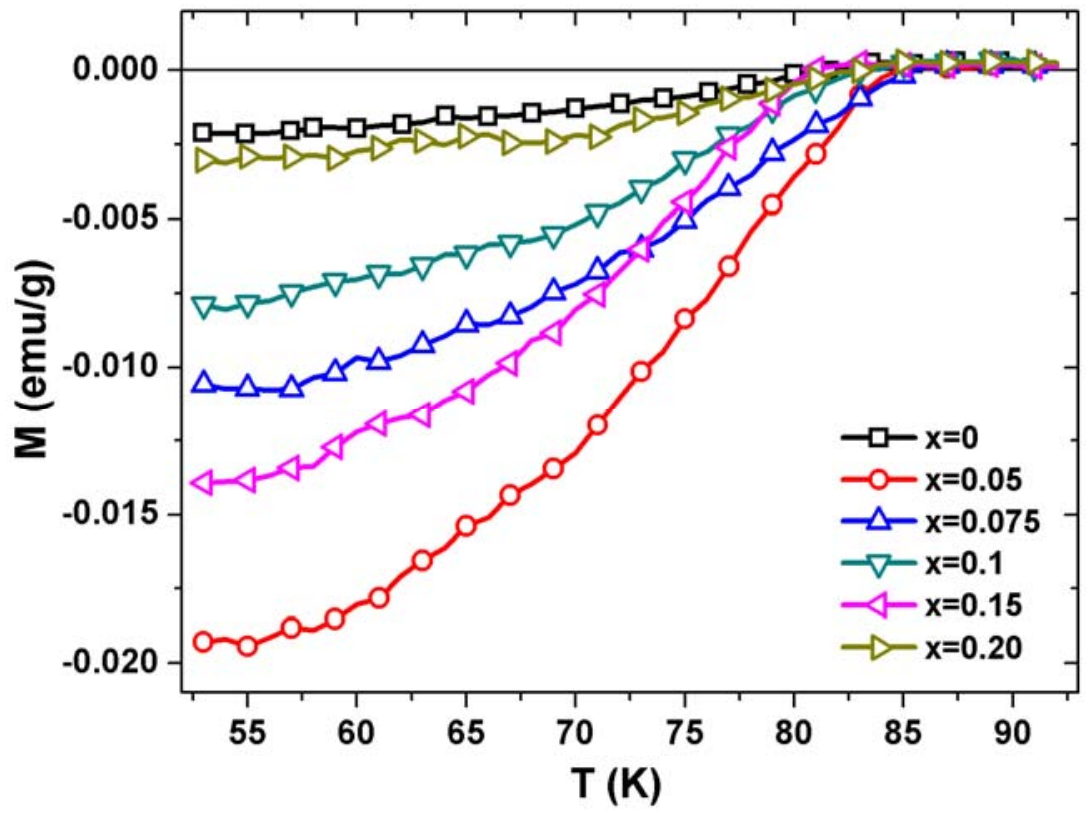


Figure 5

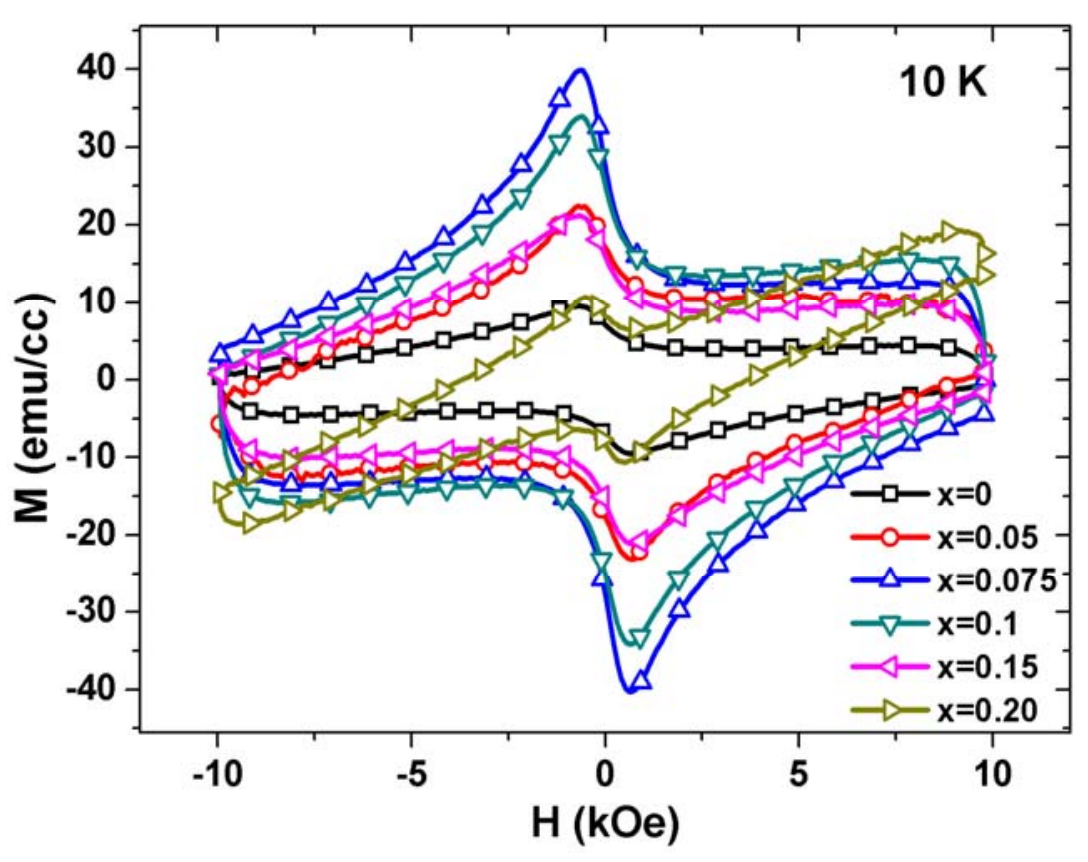


Figure 6

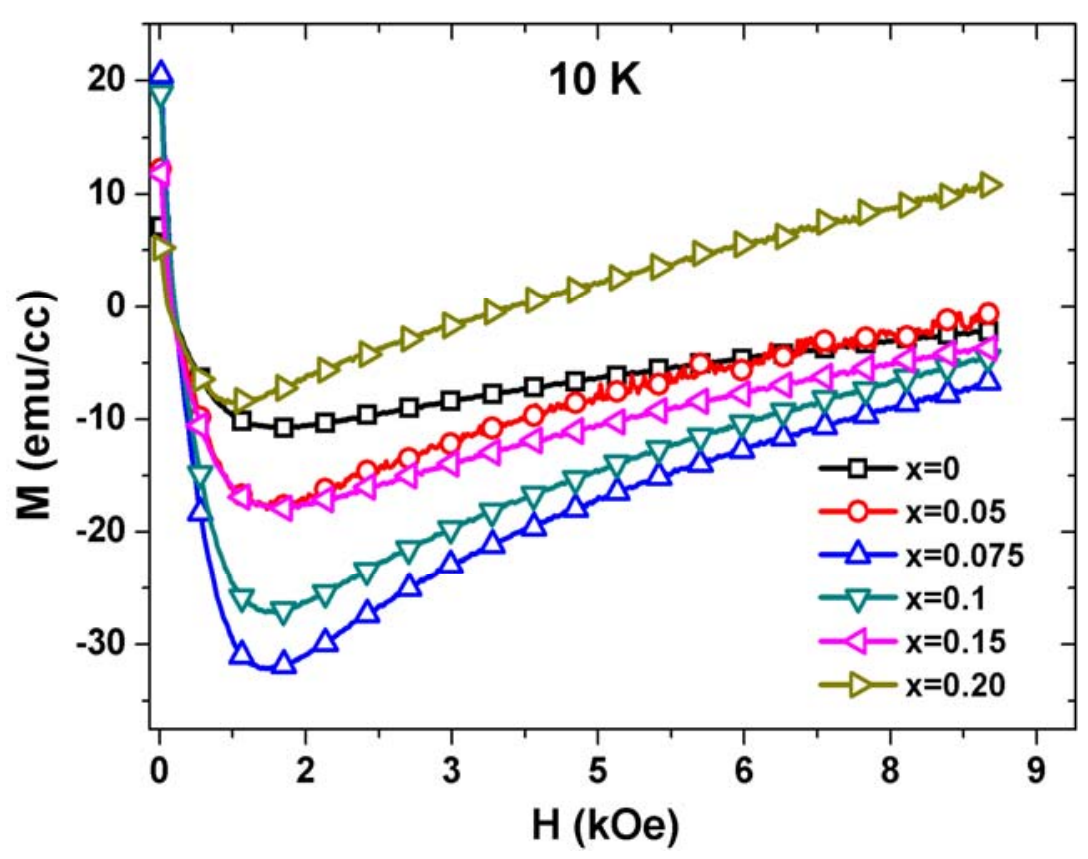


Figure 7

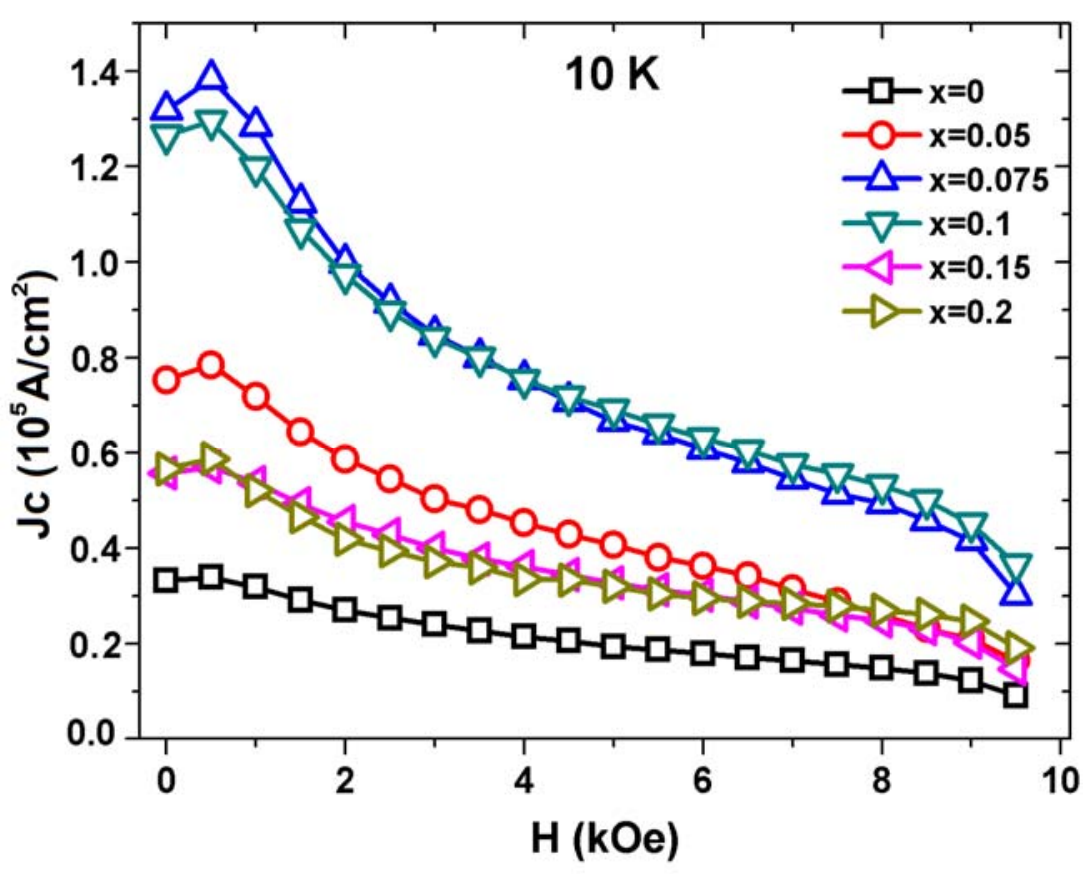


Figure 8

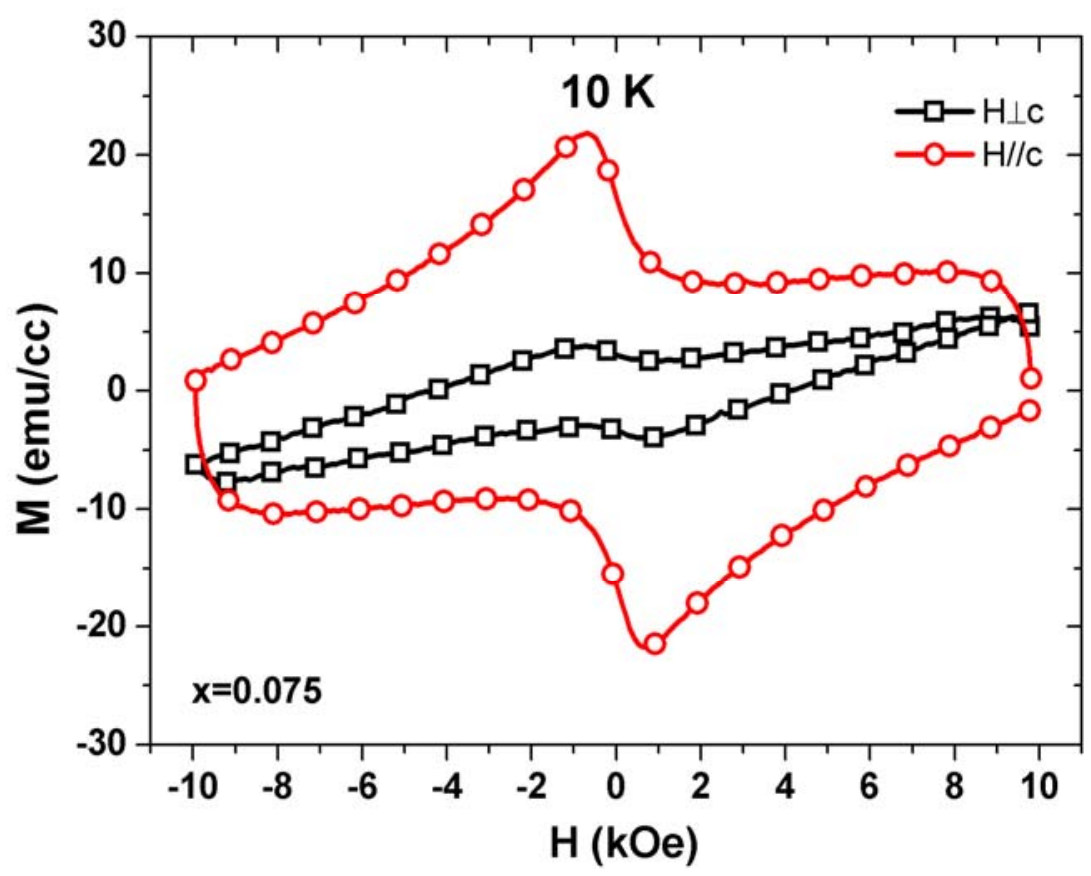


Figure 9

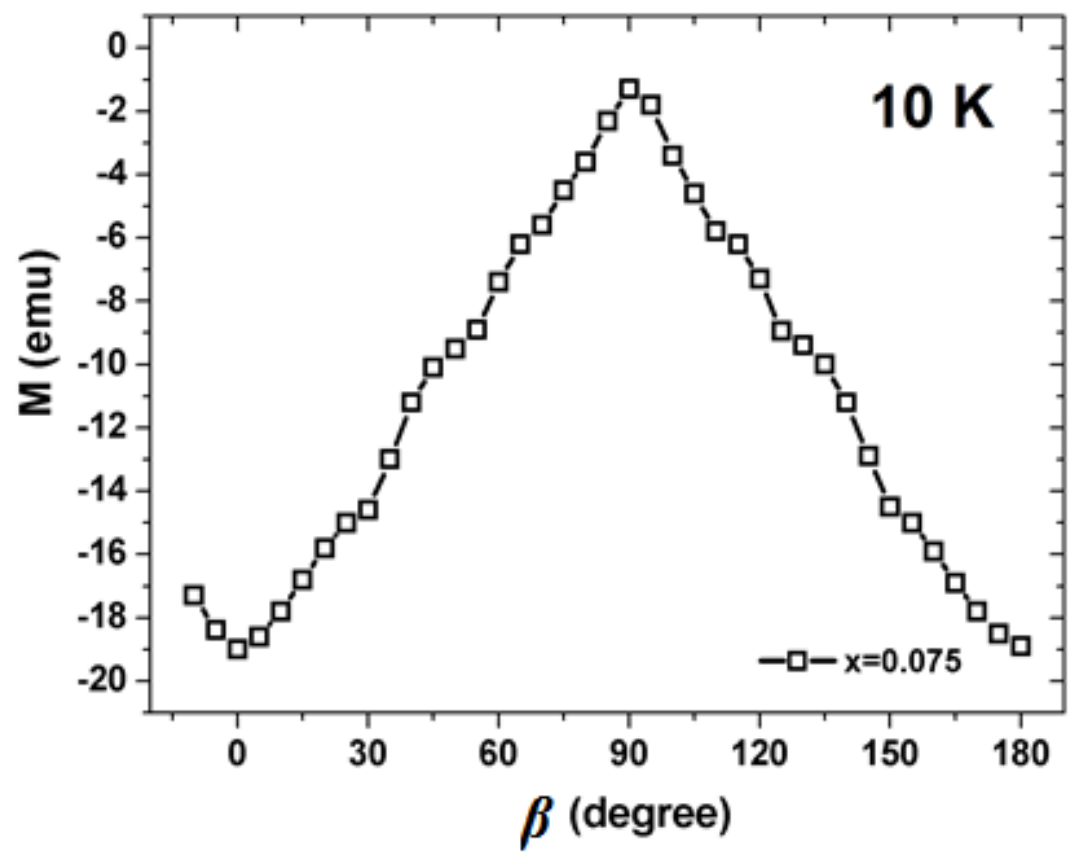

